\title{
ANALISIS EFEKTIFITAS MESIN BLOWING DENGAN MENGGUNAKAN METODE OVERALL EQUIPMENT EFFECTIVENESS SEBAGAI DASAR USULAN PERBAIKAN (STUDI KASUS : UD. KARUNIA PLASTIK)
}

\author{
Mughni Murtadlo ${ }^{1}$, Deny Andesta ${ }^{2}$, Elly Ismiyah ${ }^{3}$ \\ ${ }^{1}$ Mahasiswa Teknik Industri, Fakultas Teknik, Universitas Muhammadiyah Gresik \\ ${ }^{2,3}$ Dosen Teknik Industri, Fakultas Teknik, Universitas Muhammadiyah Gresik Jl. Sumatera No. 101 GKB- \\ Gresik 61121, Jawa Timur, Indonesia \\ Email : gendorkool21@gmail.com
}

\begin{abstract}
ABSTRAK
Pemeliharaan dan penanganan mesin yang tidak tepat dapat menyebabkan menurunnya tingkat produktivitas dan efisiensi mesin. UD. Karunia Plastik merupakan perusahan yang memproduksi plastik kemasan. Mesin yang beroperasi secara terus menerus dituntut dapat memenuhi target yang telah di tetapkan dengan tingkat efektivitas yang tinggi. Namun seringkali proses produksi terhambat akibat terjadinya kerusakan komponen mesin.

Penelitian ini menggunakan Overall Equipment Effectiveness (OEE) dan Failure Mode and Effects Analysis (FMEA) sebagai langkah memperbaiki permasalahan yang ada. OEE digunakan untuk mengetahui nilai efektifitas mesin dan penyebab masalah dapat diselesaikan dengan menggunakan FMEA.

Penelitian yang dilakukan pada Desember 2017 - Februari 2018 menghasilkan nilai Availability sebesar 84,57\%, nilai Performance sebesar 82,49\%, nilai Rate Of Quality sebesar 92,88\% dan didapatkan nilai OEE 64,79\%. Kemudian dilanjutkan dengan pengukuran OEE Six Big Losses untuk mengetahui besarnya efisiensi yang hilang pada keenam faktor Six Big Losses. Dari keenam faktor tersebut Idle and Minor Stoppages Losses adalah faktor terbesar yaitu sebesar 41,34\%, kemudian di ikuti Reduced Speed Losses 30,22\%, Setup and Adjusment Losses 12,22\%, Defect Losses 4,96\%, Equipment Failure Losses 3,21\% dan Reduced Yield 0\%. Berdasarkan analisis menggunakan FMEA, dapat diketahui bahwa penyebab kegagalan yang akan diperbaiki sesuai urutan prioritas adalah Mengganti komponen mesin yang sudah tua dan pemeliharaan mesin berkala.
\end{abstract}

Kata Kunci : Overall Equipment Effectiveness (OEE), Six Big Losses, Failure Mode And Effect Analysis (FMEA).

\section{Pendahuluan}

Di era kompetisi global yang pesat seperti sekarang ini, perkembangan teknologi yang semakin kompetitif membuat kita untuk lebih membuka diri dalam menerima perubahan yang terjadi akibat perkembangan tersebut. Dari waktu ke waktu, pengembangan teknologi terus dilakukan dengan tujuan mempermudah aktifitas manusia. Fenomena ini telah kita rasakan di segala aspek kehidupan, termasuk di bidang industri. Semua industri saling berlomba dalam meningkatkan kualitas dan produktifitas untuk dapat menjadi produsen yang berkompeten dan mampu bersaing di pasar nasional maupun internasional. Persaingan yang ketat ini, menuntut setiap perusahaan akan melakukan perbaikan secara terus-menerus guna membenahi sistem yang ada di perusahaan tersebut terutama masalah efektifitas dalam bekerja. Pembenahan tersebut dilakukan untuk menjaga dan meningkatkan kualitas serta tingkat produktifitas suatu produk. Untuk mengetahui produktifitas dari aktifitas produksi yang telah dilakukan, perlu dilakukan pengukuran berdasarkan faktor penunjang produktifitas dan kondisi riil di area produksi.

UD. Karunia Plastik adalah perusahaan plastik yang berdiri pada tahun 2007 dan berlokasi di Mojosari, Mojokerto. Jenis produk yang dihasilkan adalah berbagai plastik kemasan dengan bermacam-macam ukuran sesuai permintaan dan kebutuhan konsumen yang digunakan dalam berbagai produk makanan,minuman, dan juga lainnya.

Dalam pelaksanaan proses produksinya banyak terjadi hambatan-hambatan yang mempengaruhi kualitas produk, hal ini dipengaruhi oleh berbagai faktor, salah satunya yaitu faktor mesin dimana faktor ini cukup penting dalam menghasilkan produk. Di Bagian produksi sendiri telah dilakukan pengukuran performance kinerja mesin atau peralatan dengan hanya menggunakan acuan target produksi pihak perusahaan dari setiap mesin dan peralatan yang ada. Begitu juga dengan kebijakan pemeliharaan mesin / peralatan yang diterapkan oleh pihak perusahaan dengan melakukan kebijakan corrective maintanance yang dimana dilakukan untuk mengetahui kerusakan alat atau spare parts jika hanya ada plastik cacat yang disebabkan adanya kerusakan pada alat atau spare parts di mesin tersebut, Jika hanya mengacu pada target perusahaan dari setiap mesin dan peralatan sebagai dasar alat pengukuran performa kinerja mesin/peralatan dan juga kebijakan corrective maintenence dari pihak perusahaan dirasa tidak cukup untuk dapat mengetahui secara detail permasalahan yang ada pada mesin dan peralatan dan seringkali dianggap tidak efektif dan efisien. 


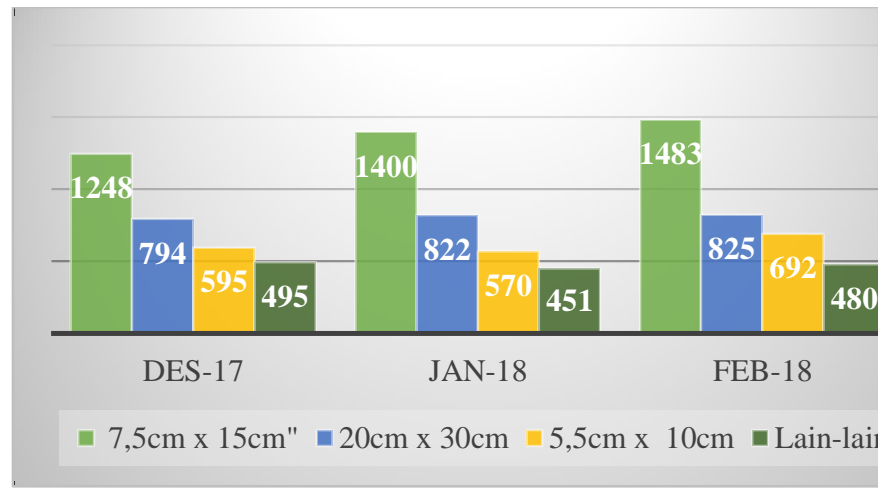

Gambar 1 Data Demand Plastik Bulan Desember 2017 Februari 2018

Berdasarkan gambar di atas, produksi di UD. Karunia Plastik dilakukan dengan Make To Order (MTO), diproduksi sesuai permintaan konsumen. Dapat diketahui bahwa jumlah produksi plastik jenis plastik ukuran $7,5 \mathrm{~cm} \times 15 \mathrm{~cm}$ semakin meningkat. Dengan semakin meningkatnya permintaan untuk jenis plastik ukuran $7,5 \mathrm{~cm}$ x $15 \mathrm{~cm}$ maka UD. Karunia Plastik berusaha meningkatkan produksinya dengan mengoptimalkan mesin yang ada guna didapat produktivitas dan memenuhi permintaan konsumen.

Peningkatan permintaan terhadap produk plastik untuk jenis ukuran $7,5 \mathrm{~cm}$ x $15 \mathrm{~cm}$ pun harus diimbangi dengan produktivitas kinerja mesin dan peralatan serta kualitas produk yang tetap terjaga. Akan tetapi, melihat keadaan yang seperti sekarang khususnya pada lantai produksi (Shop Floor) ditemukan adanya beberapa faktor yang mempengaruhi produktivitas diantaranya adalah sering terjadi nya downtime, efek downtime pada mesin adalah terjadinya kerusakan mesin yang mengakibatkan menurunnya kecepatan produksi, lamanya waktu setup, atau mesin menghasilkan produk yang cacat yang mengakibatkan target produksi tidak dapat terpenuhi.

Tabel 1 Data Downtime Mesin Blowing

\begin{tabular}{|c|c|c|}
\hline Bulan & Planned Downtime (menit) & Unplanned Downtime (menit) \\
\hline Desember '17 & 1500 & 630 \\
\hline Januar' 18 & 1500 & 555 \\
\hline Februar' '18 & 1500 & 565 \\
\hline
\end{tabular}

(Sumber :UD. Karunia Plastik)

Tabel 2 Data Defect Mesin Blowing

\begin{tabular}{|c|c|c|c|}
\hline \multirow{2}{*}{ Proses Blowing } & \multicolumn{2}{|c|}{ Kriteria Cacat } & \multirow{2}{*}{$\operatorname{Total}(\mathrm{Kg})$} \\
\hline & Tebal / Tipis (Kg) & Menguning $(\mathrm{Kg})$ & \\
\hline Total $(\mathrm{kg}) / 3$ bulan & 350 & 323 & 673 \\
\hline Rata-rata/hari & 5 & 4 & 9 \\
\hline
\end{tabular}

Tabel 3 Data Hasil Produksi Mesin Blowing Selama 3 Bulan

\begin{tabular}{|l|c|c|c|c|}
\hline $\begin{array}{c}\text { Proses / } \\
\text { Mesin }\end{array}$ & Tipe Produk & $\begin{array}{c}\text { Output } \\
\text { Produksi 3 } \\
\text { bulan (Kg) }\end{array}$ & $\begin{array}{c}\text { Target /hari } \\
\text { (Kg) }\end{array}$ & $\begin{array}{c}\text { Total Target 3 } \\
\text { bulan (Kg) }\end{array}$ \\
\hline \multirow{4}{*}{ Blowing } & \begin{tabular}{c} 
Ukuran $20 \mathrm{~cm} \times 30 \mathrm{~cm}$ \\
\cline { 2 - 5 }
\end{tabular} & 9791 & 150 & 11250 \\
\cline { 2 - 5 } & $\begin{array}{c}\text { Ukuran } 7,5 \mathrm{~cm} \times \\
15 \mathrm{~cm}\end{array}$ & 9418 & 200 & 15000 \\
\cline { 2 - 5 } & $\begin{array}{l}\text { Ukuran 5,5cm x } \\
10 \mathrm{~cm}\end{array}$ & 7490 & 130 & 9750 \\
(Sumber : UD. Karunia Plastik)
\end{tabular}

Dilihat pada Tabel 3 bahwa tiap proses produksi plastik terlihat adanya proses/mesin yang produksinya belum mencapai target yang ditentukan. Meskipun penggunaan mesin dilakukan secara bersamaan, akan tetapi target tiap mesin berbeda. Adanya perbedaan target pada tiap proses/mesin, dikarenakan setiap proses/mesin mempunyai karakteristik berbeda meskipun jenis yang diproduksi sama. Jadi, kesimpulannya adalah adanya proses/mesin yang produksinya belum sesuai target menunjukkan adanya suatu problem mesin yang terjadi. penelitian lebih lanjut untuk memberikan solusinya. Hal ini sesuai dengan sasaran perusahaan yang ditargetkan yaitu untuk meningkatkan produksinya dengan mengoptimalkan kinerja mesin yang ada guna mendapatkan produktifitas yang tinggi dan memenuhi permintaan pelanggan. Menurut Nakajima (1988) dalam Betrianis dan Robby (2005) perlu dilakukan usaha perbaikan pada industri manufaktur, dilihat dari segi peralatan, adalah dengan meningkatkan utilisasi peralatan yang ada seoptimal mungkin. Utilisasi dari peralatan yang ada pada rata-rata industri manufaktur adalah sekitar setengah dari kemampuan mesin yang sesungguhnya.

Dalam sistem pemeliharaan peralatan berdasarkan pada kegiatan perkiraan (predictive), perbaikan (repair), dan pemeriksaan menyeluruh (overhaul). Hal ini disebabkan kurang efektifnya sistem atau metode yang mampu mengukur kinerja peralatan. Salah satu metode pengukuran kinerja yang banyak digunakan oleh perusahaan untuk mengatasi permasalahan machinelequipment, Maka dilakukanlah perhitungan OEE.

Menurut Ansori dan Mustajib (2015) dalam Hermanto (2016) OEE merupakan metode yang digunakan sebagai alat ukur metrik dalam penerapan program TPM guna menjaga peralatan pada kondisi ideal dengan menghapuskan Six Big Losses peralatan. Selain itu, untuk mengukur kinerja dari suatu sistem produktif. Kemampuan mengidentifkasikan secara jelas akar permasalahan dan faktor penyebabnya sehingga membuat usaha perbaikan menjadi terfokus merupakan faktor utama metode ini diaplikasikan secara menyeluruh oleh banyak perusahaan di dunia. Sedangkan menurut Moubray (1992) dalam Dinda, dkk (2013) Failure Mode and Effect Analysis (FMEA) adalah metode yang digunakan untuk mengidentifikasi bentuk kegagalan 
yang mungkin menyebabkan setiap kegagalan fungsi dan untuk memastikan pengaruh kegagalan berhubungan dengan setiap bentuk kegagalan.

Tujuan dari penelitian ini adalah mengetahui nilai efektifitas pada mesin blowing dengan metode OEE

\section{Metode Penelitian}

Pada tahap ini menjelaskan kegiatan dalam melakukan penelitian secara rinci mulai dari tahapan tahapan awal melakukan penelitian serta metode yang digunakan dalam penelitian. Setiap tahapan dalam penelitian merupakan bagian yang menentukan tahapan selanjutnya, sehingga dilakukan dengan cermat agar diperoleh hasil yang tepat dan akurat. Adapun tahapan tahapan yang dilakukan sebagai berikut :

\section{Tahap Identifikasi Permasalahan}

Pada tahap ini, Identifikasi permasalahan dilakukan berdasarkan latar belakang permasalahan yang ada. Melihat kondisi awal produktivitas perusahan adalah tujuan utama yang mendasari permasalahan, hal ini juga dilakukan sebagai salah satu upaya pengembangan dan perbaikan sistem perusahaan.

\section{Tahap Studi Lapangan}

Pada tahap ini, peneliti melakukan Survey di area floor Production sebagai langkah awal dalam studi lapangan. Faktor - faktor yang diamati meliputi kondisi riil lantai produksi, kinerja mesin, kinerja operator dan prosedur - prosedur perusahaan yang telah ditetapkan. Faktor - faktor tersebut nantinya akan diambil data sebagai acuan perhitungan nilai OEE.

\section{Tahap Studi Pustaka}

Pada tahap ini, Pembelajaran terhadap situasi yang ada diterapkan dengan metode ilmiah yang sesuai. Metode yang digunakan adalah Overall Equipment Effectiveness (OEE) dan Failure Mode and Effect Analysis (FMEA).

\section{Tahap Perumusan Masalah}

Pada tahap ini, merumuskan masalah - masalah apa saja yang timbul dan teridentifikasi dari hasil pengamatan studi lapangan dan studi pustaka yang telah terkumpul dengan membandingkan harapan yang ingin dicapai. Langkah ini dilakukan untuk mengetahui masalah apa saja yang timbul sebagai acuan dalam proses perbaikan nantinya.

\section{Tahap Pengumpulan Data}

Pada tahap ini, peneliti mengumpulkan data data yang diperlukan melalui hasil studi lapangan yang nantinya digunakan untuk kebutuhan proses perhitungan OEE. Mengambil data historis perusahaan selama 3 bulan yaitu bulan Desember 2017 - Februari 2018 dengan objek pengamatan plastik ukuran $7,5 \mathrm{~cm} \times 15 \mathrm{~cm}$. meliputi availability, performance, dan quality. Kemudian mengetahui kerugian (losses) yang mempengaruhi efektifitas mesin, serta memberikan rekomendasi perbaikan menggunakan FMEA.

\section{Tahap Pengolahan Data}

- Pada tahap ini, dilakukan perhitungan faktor faktor OEE, meliputi :

1. Perhitungan Availability

Availability : $\frac{\text { Loading time-Downtime }}{\text { Loading time }} \times 100 \%$

2. Perhitungan Performance

Performance : $\frac{\text { Process Amount x Ideal Cycletime }}{\text { Operating Time }} \mathbf{x}$ $100 \%$

3. Perhitungan Rate Of Quality

Quality : $\frac{\text { Process Amount x Defect Amount }}{\text { Process Amount }} \times \mathbf{1 0 0 \%}$

4. Perhitungan OEE

OEE : Availability x Performance Efficiency $x$ Rate of Quality

- Setelah OEE diketahui, kemudian menghitung nilai six big losses

1. Downtime Losses (penurunan waktu)

a. Equipment Failure (kerugian kerusakan peralatan)

Equipment Failure : $\frac{\text { equipment failure }}{\text { loading time }} \times 100$

b. Set Up And Adjusment Losses (kerugian persiapan dan pengaturan peralatan)

Set Up And Adjusment Losses :

$\frac{\text { set up and adjusment losses }}{\text { loading time }} \times 100$

2. Speed Loss (penurunan kecepatan)

a. Idle and Minor Stoppage Losses (kerugian karena berhenti sesaat)

Idle and Minor Stoppage Losses : $\frac{\text { (target produksi-process amount)xideal cycle time }}{\text { loading time }}$

b. Reduced Speed Losses (kerugian karena penurunan kecepatan)

Reduced Speed Losses :

$\frac{(\text { actual cycle time-ideal cycle time) xprocess amount }}{\text { loading time }} \times 100$ 
3. Quality Losses (penurunan kualitas)

a. Defect Losses (kerugian karena produk cacat saat proses)

Defect Losses : $\frac{\text { (total defect } x \text { ideal cycle time) }}{\text { loading time }}$

b. Reduced Yield (kerugian karena hasil produksi rendah)

Reduced Yield :

$\underline{\text { ideal cycle time } x \text { jumlah cacat pada awal produksi }}$ loading time

- Dari six big losses akan dilakukan identifikasi jenis kegagalannya dengan metode FMEA, dengan mencari failure dan potensial failure.

- Setelah itu mencari nilai RPN, tetapi sebelum mencari nilai RPN terlebih dahulu mencari nilai severity, occurance dan detection.

- Kemudian mendapatkan nilai RPN selanjutnya akan dikomunikasikan dengan pihak perusahaan untuk mencari usulan perbaikan.

7. Tahap Analisis dan Interpretasi

Pada tahap ini akan dilakukan analisa terhadap hasil dari pengolahan data tentang nilai OEE yang telah dicapai. Memberikan suatu usulan perbaikan kepada perusahaan berdasarkan hasil analisis faktor pencapaian OEE dan analisis masalah kritisnya. Kemudian mendiskusikan hasil analisis tersebut dengan pihak perusahaan.

\section{Tahap Penarikan Kesimpulan dan Saran}

Pada tahap ini, peneliti melakukan penarikan kesimpulan secara umum berdasarkan hasil penelitian yang sesuai dengan tujuan penelitian yang telah ditentukan. Serta memberikan saran - saran yang berguna bagi kemajuan perusahaan dan penelitian selanjutnya.

\section{Pengumpulan Data}

Pengumpulan dan pengolahan data pada penilitian ini dilakukan dalam satu periode yaitu pada bulan Desember 2017 sampai dengan Februari 2018.

Data hasil produksi plastik ukuran $7,5 \mathrm{~cm} \mathrm{x}$ $15 \mathrm{~cm}$ pada mesin Blowing dapat dilihat pada Tabel 4. Data produk plastik cacat ukuran $7,5 \mathrm{~cm}$ x $15 \mathrm{~cm}$ pada mesin blowing dapat dilihat pada Tabel 5. Data rincian waktu kerja dapat dilihat pada Tabel 6. Data rincian waktu kerja mesin blowing dapat dilihat pada Tabel 7. Data unplanned downtime pada mesin Blowing dapat dilihat pada Tabel 8. Data planned downtime pada mesin Blowing dapat dilihat pada Tabel 9. Data setup time pada mesin blowing dapat dilihat pada Tabel 10. Data equipment failure pada mesin Blowing dapat dilihat pada Tabel 11.

Tabel 4 Data Hasil Produksi Plastik Ukuran 7,5cm x 15cm Pada Bulan Desember 2017 - Februari 2018 Pada Mesin Blowing.

\begin{tabular}{|c|c|c|}
\hline Bulan & Output / Process Amount $(\mathrm{Kg})$ & Target Produksi (Kg) \\
\hline Desember '17 & 3.139 & 5.000 \\
\hline Januari '18 & 3.137 & 5.000 \\
\hline Februari '18 & 3.142 & 5.000 \\
\hline Total /3 bulan & 9.418 & 15.000 \\
\hline Rata-Rata $(\mathrm{Kg}) / 3$ bulan & 125 & 200 \\
\hline
\end{tabular}

(Sumber : UD. Karunia Plastik)

Tabel 5 Data Produk Cacat Pada Bulan Desember 2017 - Februari 2018 Pada Mesin Blowing

\begin{tabular}{|c|c|c|c|}
\hline \multirow{2}{*}{ Bulan } & \multicolumn{2}{|c|}{ Kriteria Cacat } & \multirow{2}{*}{ Total (Kg) } \\
\cline { 2 - 3 } & Tebal / Tipis (Kg) & Menguning (Kg) & \\
\hline Desember '17 & 126 & 153 & 279 \\
\hline Januari '18 & 119 & 97 & 216 \\
\hline Februari '18 & 105 & 73 & 178 \\
\hline Total (Kg)/3 bulan & 350 & 323 & 673 \\
\hline Rata-Rata (Kg)/3 bulan & 5 & 4 & 9 \\
\hline
\end{tabular}

(Sumber : UD. Karunia Plastik)

Tabel 6 Data Rincian Waktu Kerja

\begin{tabular}{|c|c|c|}
\hline No & Bulan & Waktu Kerja / Availaibility Time (menit) \\
\hline 1 & Desember '17 & 15.000 \\
\hline 2 & Januari '18 & 15.000 \\
\hline 3 & Februari '18 & 15.000 \\
\hline \multicolumn{3}{|c|}{ Total / 3 bulan } \\
(Sumber : UD. Karunia Plastik)
\end{tabular}

Tabel 7 Data Rincian Waktu Kerja Mesin Blowing.

\begin{tabular}{|c|c|c|c|c|}
\hline No & Bulan & $\begin{array}{c}\text { Waktu Kerja/ } \\
\text { Availaibility } \\
\text { Time (menit) }\end{array}$ & $\begin{array}{c}\text { Set Suhu Elemen/ } \\
\text { Planned Downtime } \\
\text { (menit) }\end{array}$ & $\begin{array}{c}\text { Waktu Kerja } \\
\text { Mesin / Loading } \\
\text { Time (menit) }\end{array}$ \\
\hline 1 & Desember '17 & 15.000 & 1.500 & 13.500 \\
\hline 2 & Januari '18 & 15.000 & 1.500 & 13.500 \\
\hline 3 & Februari '18 & 15.000 & 1.500 & 13.500 \\
\hline \multicolumn{2}{|c|}{ Total /3 bulan } & 45.000 & 4.500 & 40.500 \\
\hline
\end{tabular}

Tabel 8 Data Unplanned Downtime Pada Bulan Desember 2017 - Februari 2018 Pada Proses Blowing. 


\begin{tabular}{|c|c|c|c|c|c|}
\hline No & Bulan & $\begin{array}{c}\text { Ganti Cetak } \\
\text { Ukuran (menit) }\end{array}$ & $\begin{array}{c}\text { Bearing Roll } \\
\text { Kendor (menit) }\end{array}$ & $\begin{array}{c}\text { Kabel Elemen } \\
\text { Putus (menit) }\end{array}$ & $\begin{array}{c}\text { Unplanned } \\
\text { Downtime } \\
\text { (menit) }\end{array}$ \\
\hline 1 & Desember '17 & 170 & 280 & 180 & 630 \\
\hline 2 & Januari '18 & 150 & 220 & 185 & 555 \\
\hline 3 & Februari '18 & 130 & 210 & 225 & 565 \\
\hline \multicolumn{2}{|c|}{ Total } & 450 & 710 & 590 & 1.750 \\
\hline
\end{tabular}

Tabel 9 Data Planned Downtime Pada Bulan Desember 2017 - Februari 2018 Pada Proses Blowing.

\begin{tabular}{|c|c|c|c|}
\hline NO & Plammed Downtime & Bulan & Waktu (menit) \\
\hline \multirow{3}{*}{1} & \multirow{3}{*}{ Set Suhu Elemen } & Desember '17 & 1.500 \\
\cline { 3 - 4 } & & Januari '18 & 1.500 \\
\cline { 3 - 4 } & & Februari '18 & 1.500 \\
\hline \multicolumn{3}{|c|}{ Total } \\
\hline
\end{tabular}

(Sumber : UD. Karunia Plastik)

Tabel 10 Data Equipment Failure Pada Bulan Desember 2017 - Februari 2018 Pada Proses Blowing.

\begin{tabular}{|c|c|c|c|c|}
\hline No & Bulan & $\begin{array}{l}\text { Bearing Roll Kendor } \\
\text { (menit) }\end{array}$ & $\begin{array}{l}\text { Kabel Elemen } \\
\text { Putus (menit) }\end{array}$ & $\begin{array}{c}\text { Equipment } \\
\text { Failure (menit) }\end{array}$ \\
\hline 1 & Desember ' 17 & 280 & 180 & 460 \\
\hline 2 & Januari '18 & 220 & 185 & 405 \\
\hline 3 & Februari '18 & 210 & 225 & 435 \\
\hline & Total & 710 & 590 & 1.300 \\
\hline
\end{tabular}

Tabel 11 Data Setup Pada Bulan Desember 2017 Februari 2018 Pada Proses Blowing.

\begin{tabular}{|c|c|c|c|c|}
\hline No & Bulan & $\begin{array}{c}\text { Set Suhu Temperatur } \\
\text { (menit) }\end{array}$ & $\begin{array}{l}\text { Ganti Ukuran } \\
\text { (menit) }\end{array}$ & $\begin{array}{c}\text { Setup Time } \\
\text { (menit) }\end{array}$ \\
\hline 1 & Desember ' 17 & 1.500 & 170 & 1.670 \\
\hline 2 & Januari '18 & 1.500 & 150 & 1.650 \\
\hline 3 & Februari ‘18 & 1.500 & 130 & 1.630 \\
\hline & Total & 4.500 & 297 & 1.300 \\
\hline
\end{tabular}

\section{Hasil dan Pembahasan}

Data yang telah dikumpulkan pada penelitian ini adalah data hasil produksi, data produk cacat, data rincian waktu kerja, data rincian waktu kerja mesin, data unplanned downtime, data planned downtime, data equipment failure dan data setup time selama periode bulan Desember 2017 - Februari 2018. Data tersebut kemudian dilakukan pengolahan data. Terdapat 3 tahap perhitungan dan analisis data yang akan dilakukan yaitu perhitungan dengan menggunakan metode Overall Equipment Effectiveness (OEE), Six Big Losses dan Failure Mode and Effect Analysis (FMEA).

\subsection{Analisis Perhitungan Nilai OEE}

Perhitungan Overall Equipment Effectiveness (OEE) dilakukan untuk mengetahui tingkat efektifitas penggunaan mesin blowing selama periode Desember 2017 - Februari 2018.

\section{1) Pengukuran Nilai Availability Ratio}

Availability ratio adalah rasio yang menunjukkan penggunaan waktu yang tersedia untuk kegiatan operasi mesin atau peralatan. Adapun data-data yang digunakan dalam pengukuran availability ratio ini adalah hari kerja, planned downtime, unplanned downtime. Perhitungan nilai availability ratio pada mesin blowing dapat dilihat pada Tabel 12.

Tabel 12 Perhitungan Nilai Availability Ratio

\begin{tabular}{|c|c|c|c|c|c|c|}
\hline Bulan & $\begin{array}{c}\text { Availaibil } \\
\text { ity Time } \\
\text { (menit) }\end{array}$ & $\begin{array}{c}\text { Planned } \\
\text { Downtime } \\
\text { (menit) }\end{array}$ & $\begin{array}{c}\text { Unplanned } \\
\text { Downtime } \\
\text { (menit) }\end{array}$ & $\begin{array}{c}\text { Loading } \\
\text { Time } \\
\text { (menit) }\end{array}$ & $\begin{array}{c}\text { Operating } \\
\text { Time } \\
\text { (menit) }\end{array}$ & $\begin{array}{c}\text { Availabilty } \\
\text { Ratio (\%) }\end{array}$ \\
\hline Desember '17 & 15.000 & 1.500 & 630 & 13.500 & 11.370 & $84,22 \%$ \\
\hline Januari '18 & 15.000 & 1.500 & 555 & 13.500 & 11.445 & $84,78 \%$ \\
\hline Februari '18 & 15.000 & 1.500 & 565 & 13.500 & 11.435 & $84,70 \%$ \\
\hline \multicolumn{7}{|c|}{ Rata-Rata } \\
\hline
\end{tabular}

Contoh perhitungan Availability Ratio untuk bulan Desember 2017 :

Downtime : Planned Downtime + Unplanned Downtime

$: 1.500$ menit +630 menit $=2.130$ menit

Loading Time : Availaibility Time - Planned Downtime

$$
: 15.000-1.500=13.500 \text { menit }
$$

$$
\begin{aligned}
\text { Availability } & : \frac{\text { Loading time-Downtime }}{\text { Loading time }} \times 100 \% \\
& : \frac{13.500-2.130}{13.500} \times 100 \% \\
& : \mathbf{8 4 , 2 2 \%}
\end{aligned}
$$

2) Pengukuran Nilai Performance Efficiency

Performance efficiency adalah rasio yang menunjukkan kemampuan peralatan dalam menghasilkan produk yang dinyatakan dengan presentase. Adapun data-data yang digunakan dalam pengukuran performance efficiency, yaitu ideal cycle time, process amount dan operating time. Perhitungan nilai performance efficiency pada mesin blowing dapat dilihat pada Tabel 13.

Tabel 13 Perhitungan Nilai Performance Efficiency

\begin{tabular}{|c|c|c|c|c|}
\hline Bulan & $\begin{array}{c}\text { Output/Process } \\
\text { Amount }(\mathrm{Kg})\end{array}$ & $\begin{array}{c}\text { Ideal Cycle Time } \\
\text { (menit/Kg) }\end{array}$ & $\begin{array}{c}\text { Operating Time } \\
\text { (menit) }\end{array}$ & $\begin{array}{c}\text { Performance } \\
\text { Efficiency (\%) }\end{array}$ \\
\hline Desember '17 & 3.139 & 3 & 11.370 & $82,82 \%$ \\
\hline Januari '18 & 3.137 & 3 & 11.445 & $82,22 \%$ \\
\hline Februari '18 & 3.142 & 3 & 11.435 & $82,43 \%$ \\
\hline \multicolumn{4}{|c|}{ Rata-Rata } & $82,49 \%$ \\
\hline
\end{tabular}


Contoh perhitungan Performance Efficiency untuk bulan Desember 2017 :

Operating Time : Loading Time-Downtime

$$
: 13.500-2.130=11.370 \text { menit }
$$

Actual Cycle Time : Operating Time / Output Produksi

$$
: 13.500 / 3.139=4,30(\text { menit } / \mathrm{Kg})
$$

Ideal Cycle Time : Availability Time / Target Produksi

$$
: 15.000 / 5.000=3(\text { menit } / \mathrm{Kg})
$$

Performance

$\frac{\text { Process Amount x Ideal Cycletime }}{\text { Operating Time }} \times 100 \%$

$$
\begin{aligned}
& : \frac{3.139 \times 3}{11.370} \times 100 \% \\
& : \mathbf{8 2 , 2 2 \%}
\end{aligned}
$$

\section{3) Pengukuran Nilai Rate Of Quality}

Rate Of Quality adalah rasio yang menunjukkan kemampuan peralatan dalam menghasilkan produk yang sesuai dengan standar. Adapun data-data yang digunakan dalam pengukuran rate of quality, yaitu jumlah produksi dan produk cacat. Perhitungan nilai rate of quality pada mesin blowing dapat dilihat pada Tabel 14.

Tabel 14 Perhitungan Nilai Rate Of Quality

\begin{tabular}{|c|c|c|c|}
\hline Bulan & $\begin{array}{c}\text { Output/Process } \\
\text { Amount }(\mathrm{Kg})\end{array}$ & Defect $(\mathrm{Kg})$ & Rate Of Quality (\%) \\
\hline Desember'17 & 3.139 & 279 & $91,11 \%$ \\
\hline Januari '18 & 3.137 & 215 & $93,14 \%$ \\
\hline Februari'18 & 3.142 & 176 & $94,40 \%$ \\
\hline \multicolumn{3}{|c|}{ Rata-Rata } & $\mathbf{9 2 , 8 8 \%}$ \\
\hline
\end{tabular}

Contoh perhitungan Rate of Quality untuk bulan Desember 2017 :

$$
\begin{aligned}
\text { Quality } & : \frac{\text { Process Amount } x \text { Defect Amount }}{\text { Process Amount }} \times 100 \% \\
& : \frac{3.139-279}{3.139} \times 100 \% \\
& : \mathbf{9 1 , 1 1 \%}
\end{aligned}
$$

\begin{tabular}{|c|c|c|c|c|}
\hline Bulan & $\begin{array}{l}\text { Availabilty } \\
\text { Ratio (\%) }\end{array}$ & $\begin{array}{l}\text { Performance } \\
\text { Efficiency (\%) }\end{array}$ & $\begin{array}{c}\text { Rate Of Quality } \\
(\%)\end{array}$ & $\mathrm{OEE}(\%)$ \\
\hline Desember ' 17 & $84.22 \%$ & $82,82 \%$ & $91.11 \%$ & $63,55 \%$ \\
\hline Januari '18 & $84.78 \%$ & $82,22 \%$ & $93.14 \%$ & $64,92 \%$ \\
\hline Februari'18 & $84.70 \%$ & $82,43 \%$ & $94.40 \%$ & $65,90 \%$ \\
\hline \multicolumn{4}{|c|}{ Rata-Rata } & $64.79 \%$ \\
\hline
\end{tabular}

4. Perhitungan Nilai Overall Equipment Effectiveness (OEE)

Setelah nilai availability ratio, performance ratio dan quality ratio didapatkan, maka selanjutnya adalah menghitung nilai OEE. Hasil perhitungan nilai OEE pada mesin blowing dapat dilihat pada Tabel 15

Tabel 15 Perhitungan Nilai OEE
Contoh perhitungan nilai OEE pada bulan Desember 2017:

\section{OEE : (Availability x Performance x Quality)$$
\text { : ( } 84,22 \% \times 82,82 \% \times 91,11 \%)
$$$$
\text { : } 63,55 \%
$$

Berdasarkan perhitungan yang telah dilakukan, didapatkan rata-rata nilai OEE untuk bulan Desember 2017 - Februari 2018 adalah sebesar 64,79\%. Nilai tersebut masih jauh dari nilai standar ideal OEE kelas dunia yaitu $85 \%$. Dari situ terlihat bahwa efektifitas dari mesin blowing secara keseluruhan masih memerlukan evaluasi untuk dilakukan perbaikan dalam upaya meningkatan efektifitas mesin.

\subsection{Analisis Perhitungan Nilai Six Big Losses}

Analisis OEE menyoroti 6 kerugian utama (six big losses) penyebab peralatan produksi tidak beroperasi secara normal. Dari 6 kerugian utama dikelompokkan menjadi 3 yaitu downtime losses, speed losses, quality losses. Berikut pengelompokkan 6 kerugian utama (six big losses), yang diantaranya adalah:

\section{Downtime Losses}

Downtime adalah waktu yang terbuang, dimana proses produksi tidak berjalan yang biasanya diakibatkan oleh kerusakan mesin. Downtime terdiri dari 2 macam kerugian yaitu :

\section{a) Equipment Failure Losses}

Merupakan kerugian yang diakibatkan oleh kerusakan mesin dan peralatan. Kerusakan peralatan atau spare part secara mendadak sehingga proses produksi terhenti, kerusakan peralatan yang sering terjadi adalah akibat bearing roll kendor dan kabel elemen putus. Perhitungan equipment failure losses dapat dilihat pada Tabel 16

Tabel 16 Data Perhitungan Equipment Failure Losses

\begin{tabular}{|c|c|c|c|}
\hline Bulan & $\begin{array}{c}\text { Equipment Failure } \\
\text { (menit) }\end{array}$ & $\begin{array}{c}\text { Loading Time } \\
\text { (menit) }\end{array}$ & $\begin{array}{c}\text { Equipment Failure } \\
\text { Losses (\%) }\end{array}$ \\
\hline Desember '17 & 460 & 13.500 & $3,40 \%$ \\
\hline Januari '18 & 405 & 13.500 & $3 \%$ \\
\hline Februari '18 & 435 & 13.500 & $3,22 \%$ \\
\hline Total & 1.300 & 40.500 & $9,62 \%$ \\
\hline \multicolumn{3}{|c|}{ Rata-Rata } & $\mathbf{3 , 2 1 \%}$ \\
\hline
\end{tabular}


Contoh perhitungan Equipment Failure Losses untuk bulan Desember 2017 :

Equipment Failure Losses :

$\frac{\text { Equipment failure time }}{\text { loading time }} \times 100 \%$

: 280 ( bearing roll kendor ) +180 ( kabel elemen putus ) $: 460$

$: \frac{460}{13.500} \times 100 \%$

\section{$: \mathbf{3 , 4 0} \%$}

\section{b) Setup and Adjusment Losses}

Merupakan kerugian yang terjadi karena setelah setup dilakukan, peralatan/ mesin berhenti dikarenakan adanya waktu yang tercuri waktu setup yang lama. Perhitungan setup and adjustment losses dapat dilihat pada Tabel 17.

Tabel 17 Data Perhitungan Setup and Adjusment Losses

\begin{tabular}{|c|c|c|c|}
\hline Bulan & $\begin{array}{c}\text { Setup Time } \\
\text { (menit) }\end{array}$ & $\begin{array}{c}\text { Loading Time } \\
\text { (menit) }\end{array}$ & $\begin{array}{c}\text { Setup And Adjusment } \\
\text { Losses (\%) }\end{array}$ \\
\hline Desember '17 & 1.670 & 13.500 & $12,37 \%$ \\
\hline Januari' '18 & 1.650 & 13.500 & $12,22 \%$ \\
\hline Februari' 18 & 1.630 & 13.500 & $12,07 \%$ \\
\hline Total & 4.950 & 13.500 & $36,66 \%$ \\
\hline \multicolumn{3}{|c|}{ Rata-Rata } & $\mathbf{1 2 , 2 2 \%}$ \\
\hline
\end{tabular}

Contoh perhitungan Setup and Adjusment Losses untuk bulan Desember 2017 :

Setup and Adjusment Losses : $\frac{\text { Setup and adjusment }}{\text { loading time }} \times$ $100 \%$

: 1.500 ( set suhu temperatur) +170 ( ganti ukuran) : 1.670

: $\frac{1.670}{13.500} \times 100 \%$

$$
: 12,37 \%
$$

\section{Speed Losses}

Speed losses adalah suatu keadaan dimana kecepatan proses produksi terganggu, sehingga produksi tidak mencapai tingkat yang diharapkan. Speed losses terdiri dari dua macam kerugian, yaitu :

\section{a) Idle and Minor Stoppage Losses}

Merupakan kerugian yang disebabkan mesin berhenti sesaat. Hal ini disebabkan karena lamanya setting suhu elemen dan ganti ukuran cetakan, kerusakan alat atau spare part pada mesin seperti bearing roll kendor dan kabel elemen putus sehingga mengakibatkan mesin berhenti secara mendadak. Perhitungan idle minor and stoppage losses dapat dilihat pada Tabel 18.
Tabel 18 Data Perhitungan Idle and Minor Stoppage Losses

\begin{tabular}{|c|c|c|c|c|c|}
\hline Bulan & $\begin{array}{c}\text { Target } \\
\text { Produksi } \\
\text { (Kg) }\end{array}$ & $\begin{array}{c}\text { Output/Process } \\
\text { Amount }(\mathrm{Kg})\end{array}$ & $\begin{array}{c}\text { Ideal Cycle } \\
\text { Time (menit } \\
\text { /Kg) }\end{array}$ & $\begin{array}{c}\text { Loading Time } \\
\text { (menit) }\end{array}$ & $\begin{array}{c}\text { Idle And } \\
\text { Minor } \\
\text { Stoppage } \\
\text { Losses (\%) }\end{array}$ \\
\hline $\begin{array}{c}\text { Desember } \\
\text { '17 }\end{array}$ & 5.000 & 3.139 & 3 & 13.500 & $41,35 \%$ \\
\hline Januari' 18 & 5.000 & 3.137 & 3 & 13.500 & $41,40 \%$ \\
\hline Februari '18 & 5.000 & 3.142 & 3 & 13.500 & $41,28 \%$ \\
\hline Total & 15.000 & 9.418 & 9 & 40.500 & $124,03 \%$ \\
\hline \multicolumn{5}{|c|}{ Rata - Rata } \\
\hline \multicolumn{5}{|c|}{} \\
\hline
\end{tabular}

Contoh perhitungan Idle and Minor Stoppage Losses untuk bulan Desember 2017:

Idle And Minor Stoppage Losses :

$: \frac{(\text { target produksi-process amount }) \times \text { ideal cycle time }}{\text { loading time }} \times 100 \%$

$: \frac{(5.000-3.139) \times 3}{13.500} \times 100 \%$

\section{$: 41,35 \%$}

\section{a) Reduce Speed Losses}

Merupakan kerugian yang terjadi karena penurunan kecepatan mesin sehingga mesin tidak dapat beroperasi dengan maksimal. Perhitungan reduce speed losses dapat dilihat pada Tabel 19.

Tabel 19 Data Perhitungan Reduce Speed Losses

\begin{tabular}{|c|c|c|c|c|c|}
\hline Bulan & $\begin{array}{c}\text { Output/Process } \\
\text { Amount }(\mathrm{Kg})\end{array}$ & $\begin{array}{c}\text { Actual Cycle } \\
\text { Time }(\mathrm{menit} \\
/ \mathrm{Kg})\end{array}$ & $\begin{array}{c}\text { Ideal Cycle } \\
\text { Time (menit } \\
/ \mathrm{Kg})\end{array}$ & $\begin{array}{c}\text { Loading Time } \\
\text { (menit) }\end{array}$ & $\begin{array}{c}\text { Reduce Speed } \\
\text { Losses }\end{array}$ \\
\hline Desember '17 & 3.139 & 4,30 & 3 & 13.500 & $30,22 \%$ \\
\hline Januari '18 & 3.137 & 4,30 & 3 & 13.500 & $30,20 \%$ \\
\hline Februari '18 & 3.142 & 4,29 & 3 & 13.500 & $30,23 \%$ \\
\hline Total & 9.418 & 12,89 & 9 & 40.500 & $90,65 \%$ \\
\hline \multicolumn{5}{|c|}{ Rata - Rata } & $\mathbf{3 0 , 2 2 \%}$ \\
\hline
\end{tabular}

Contoh perhitungan Reduce Speed Losses untuk bulan Desember 2017:

Reduce Speed Losses :

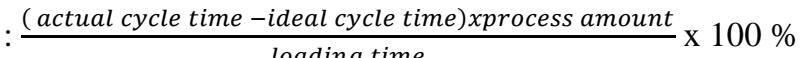

$: \frac{(4,30-3) \times 3.139}{13.500} \times 100 \%$

: $30,22 \%$

\section{Quality Losses}

Quality losses adalah suatu keadaan dimana produk yang dihasilkan tidak sesuai dengan spesifikasi yang telah ditetapkan. quality losses terdiri dari 2 macam, antara lain:

\section{a) Defect Losses}

Kerugian dikarenakan produk hasil produksi dimana produk tersebut memiliki kekurangan (cacat) setelah 
keluar dari proses produksi. Perhitungan defect losses dapat dilihat pada Tabel 20.

Tabel 20 Data Perhitungan Defect Losses

\begin{tabular}{|c|c|c|c|c|}
\hline Bulan & $\begin{array}{c}\text { Jumlah Reject/ } \\
\text { Defect (Kg) }\end{array}$ & $\begin{array}{c}\text { Ideal Cycle Time } \\
\text { (menit } / \mathrm{Kg})\end{array}$ & $\begin{array}{c}\text { Loading Time } \\
\text { (menit) }\end{array}$ & $\begin{array}{c}\text { Defect Loss } \\
(\%)\end{array}$ \\
\hline Desember '17 & 279 & 3 & 13.500 & $6,20 \%$ \\
\hline Januari '18 & 216 & 3 & 13.500 & $4,78 \%$ \\
\hline Februari '18 & 176 & 3 & 13.500 & $3,91 \%$ \\
\hline Total & 673 & 9 & 40.500 & $14,89 \%$ \\
\hline \multicolumn{4}{|c|}{ Rata-Rata } & $\mathbf{4 , 9 6 \%}$ \\
\hline
\end{tabular}

Contoh perhitungan Defect Losses untuk bulan Desember 2017:

Defect Losses :

: $\frac{\text { jumlah reject } \times \text { ideal cycle time }}{\text { loading time }} \times 100 \%$

$: \frac{279 \times 3}{13.500} \times 100 \%$

: $6,20 \%$

\section{b) Reduced Yield}

Kerugian pada awal waktu produksi hingga mencapai kondisi yang stabil. kerugian yang diakibatkan suatu keadaan dimana produk yang dihasilkan tidak sesuai standar, karena terjadi perbedaan kualitas antara waktu mesin pertama kali dinyalakan dengan pada saat mesin tersebut sudah stabil beroperasi. Perhitungan reduced yield dapat dilihat pada Tabel 21 .

Tabel 21 Data Perhitungan Reduced Yield

\begin{tabular}{|c|c|c|c|c|}
\hline Bulan & $\begin{array}{c}\text { Reduced Yield } \\
(\mathrm{Kg})\end{array}$ & $\begin{array}{c}\text { Ideal Cycle Time } \\
(\mathrm{menit} / \mathrm{Kg})\end{array}$ & $\begin{array}{c}\text { Loading Time } \\
\text { (menit) }\end{array}$ & $\begin{array}{c}\text { Reduced Yield } \\
(\%)\end{array}$ \\
\hline Desember '17 & 0 & 3 & 13.500 & $0 \%$ \\
\hline Januari' 18 & 0 & 3 & 13.500 & $0 \%$ \\
\hline Februari '18 & 0 & 3 & 13.500 & $0 \%$ \\
\hline Total & 0 & 9 & 40.500 & $0 \%$ \\
\hline \multicolumn{5}{|c|}{ Rata-Rata } \\
\hline
\end{tabular}

Contoh perhitungan Reduced Yield untuk bulan Desember 2017:

\section{Reduced Yield :}

$: \frac{\text { ideal cycle time } \times \text { jumlah cacat pada awal produksi }}{\text { loading time }} \times 100 \%$

$: \frac{3 \times 0}{13.500} \times 100 \%$

$: 0 \%$

\subsection{Failure Mode and Effect Analysis (FMEA)}

Dari hasil analisa six big losses didapatkan bahwa faktor yang paling dominan menghasilkan losses yaitu, setup and adjusment losses, idle and minor stoppage losses, dan defect losses oleh sebab itu selanjutnya akan dianalisa penyebab-penyebab kegagalan yang disebabkan oleh faktor idle and minor stoppage losses dengan menggunakan FMEA. Setelah melakukan pengamatan pada proses produksi, maka didapatkan failure mode and failure effect pada tiap kegagalan proses mesin pembuat produk plastik ukuran $7,5 \mathrm{~cm} \times 15 \mathrm{~cm}$ yaitu mesin blowing . Data ini diperoleh berdasarkan hasil wawancara serta diskusi apabila ada perbedaan penilaan dengan 1 pemilik perusahaan, 1 kepala bengkel, dan 2 operator di perusahaan UD. Karunia Plastik dengan diambil nilai rata-rata tiap responden dengan menggunakan pengisian form FMEA memberikan pembobotan terhadap faktor severity, occurrence dan detection. Hasil dari pembobotan tersebut akan menentukan akar masalah yang menjadi prioritas utama. Rating diberikan berdasarkan beberapa kategori. Data failure mode and failure effect dapat dilihat pada Tabel 22.

Tabel 22 Failure Mode and Effect Analysis

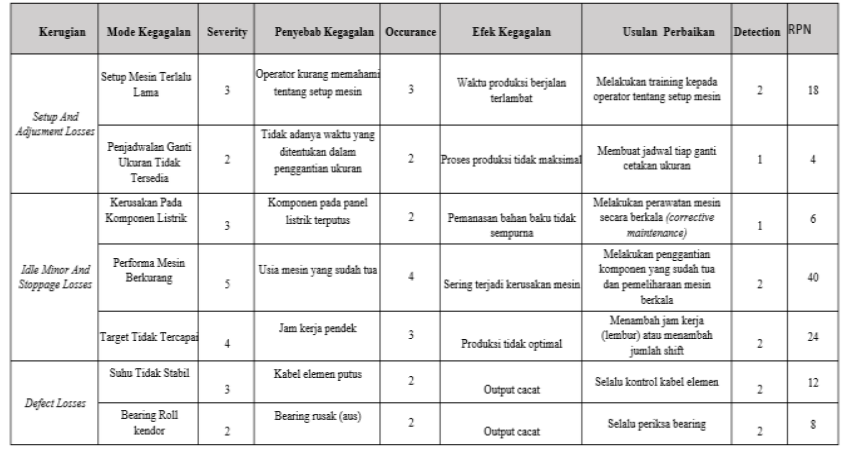

Dibawah ini adalah urutan penyebab kegagalan yang paling berpengaruh dari nilai RPN terbesar hingga nilai terkecil :

1) Performa Mesin Berkurang.

2) Target Tidak Tercapai.

3) Setup Mesin Terlalu Lama.

4) Suhu Tidak Stabil.

5) Bearing Roll Kendor.

6) Komponen Pada Panel Listrik Terputus.

7) Penjadwalan Ganti Ukuran Tidak Tersedia.

Setelah melihat mode kegagalan sesuai nilai RPN tertinggi maka selanjutnya akan usulan perbaikan seperti dibawah ini :

1. Performa mesin berkurang yang disebabkan karena faktor usia mesin dan mengakibatkan sering terjadinya kerusakan, maka usulan perbaikannya adalah melakukan penggantian komponen yang sudah tua (aus) dan pemeliharaan mesin secara berkala.

2. Target tidak tercapai dikarenakan jam kerja terlalu pendek yang mengakibatkan jumlah 
produksi kurang optimal, maka usulan perbaikannya adalah menambah jam kerja (lembur) atau menambah jumlah shift.

3. Setup mesin terlalu lama karena operator kurang memahami tentang setup, maka usulan perbaikannya yaitu, melakukan training kepada operator agar lebih mengetahui tentang setup mesin.

4. Suhu tidak stabil dikarenakan kabel elemen putus sehingga hasil ouput mengalami cacat maka usulan perbaikannya adalah operator harus selalu melakukan pengontrolan kabel elemen.

5. Bearing roll kendor dikarenakan bearing sudah rusak (aus) yang mengakibatkan hasil output cacat (tebal tipis), maka usulan perbaikannya yaitu selalu periksa keadaan bearing.

6. Kerusakan pada panel listrik yang berakibat komponen listrik putus dan pemanasan bahan baku menjadi tidak sempurna maka perbaikan yang dilakukan adalah melakukan perawatan secara berkala (corrective maintenance).

7. Penjadwalan ganti ukuran tidak tersedia mengakibatkan proses produksi tidak maksimal, maka usulannya adalah membuat jadwal tiap ganti ukuran.

\section{Kesimpulan}

Setelah melakukan perhitungan pengukuran nilai efektifitas mesin melalui pembahasan dan pengolahan data dapat dapat di tarik beberapa kesimpulan yang menjadi tujuan dari penelitian ini serta di berikan suatu usulan terhadap pihak perusahaan dalam peningkatan efektifitas mesin serta peralatan.

1. Pengukuran nilai efektifitas pada mesin blowing menggunakan OEE pada bulan Desember 2017 sampai dengan bulan Februari 2018 maka didapatkan nilai OEE sebesar :
a) Availability Rate $=84,57 \%$
b) Performance Efficiency $=82,49 \%$
c) Rate of Quality $=92,88 \%$
d) $\mathrm{OEE}=64,79 \%$

Berdasarkan hasil perhitungan OEE Dapat disimpulkan bahwa perusahaan masih belum dikatakan dalam kategori efektif dalam pengunaan mesin dan perlatannya. Karena pada perhitungan OEE dalam penelitian ini nilai Availability,
Performance, Rate Of Quality dan OEE masih dibawah nilai standar OEE kelas dunia, yang dimana seharusnya nilai Avaliability sebesar 90\%, Performance Efficiency sebesar $99 \%$, Rate Of Quality Sebesar 99\% dan OEE adalah $85 \%$.

2. Untuk mengetahui faktor - faktor penyebab masalah dari rendahnya nilai OEE, maka dilakukan perhitungan six big losses dan didapatkan nilai :

a) Equipment Failure Losses : 3,21\%

b) Set-up And Adjusment Losses : 12,22\%

c) Idle and Minor Stoppages Losses : 41,34\%

d) Reduce Speed Losses : 30,22\%

e) Defect Losses : 4,96\%

f) Reduced Yield : $0 \%$

Berdasarkan presentase tertinggi dari nilai six big losses yaitu yang pertama adalah idle and minor stoppage losses dimana nilai presentase sebesar $41,34 \%$ yaitu kerugian yang disebabkan mesin berhenti sesaat yang mengakibatkan produk plastik atau material cacat atau mengalami kerugian dan juga dari segi waktu yang mengalami idle atau botleneck. Dapat disimpulkan bahwa perusahaan belum efektif dalam mesin produksi serta peralatannya dikarenakan nilai OEE yang masih dibawah nilai OEE kelas dunia.

3. Usulan perbaikan yang diberikan untuk meningkatkan nilai OEE agar mesin dapat bekerja dengan efisien adalah :

a) Melakukan penggantian komponen yang sudah tua (aus) dan pemeliharaan mesin secara berkala agar mesin tetap dalam performasinya.

b) Menambah jam kerja (lembur) atau menambah jumlah shift agar target terpenuhi.

c) Melakukan training kepada operator agar lebih mengetahui tentang setup mesin.

d) Operator harus selalu melakukan pengontrolan kabel elemen.

e) Selalu periksa keadaan bearing.

f) Melakukan perawatan secara berkala (corrective maintenance).

g) Membuat jadwal tiap ganti ukuran. 


\section{DAFTAR PUSTAKA}

Anshori, Nachnul., \& Mustajib, M. Imron. 2013. Sistem Perawatan Terpadu (Integrated Maintanance System). Graha Ilmu, Yogyakarta.

Betrianis, Robby S. 2005. Pengukuran Nilai Overall Equipment Effectiveness Sebagai Dasar Usaha Perbaikan Proses Manufaktur Pada Lini Produksi. Jurnal Teknik Industri, Jurusan Teknik Industri, Universitas Indonesia.

Delia FR, Harsono T, Lisye F. 2014. Usulan Peningkatan Efektivitas Mesin Cetak Manual Menggunakan Metode Overall Equipment Effectiveness (OEE). Jurnal Online Institut Teknologi Nasional Reka Integra ISSN : 2338-5081, Jurusan Teknik Industri, Intitut Teknologi Nasional (Itenas), No.04, Vol.02, Bandung.
Diana A, Yanti H, Hendro P. 2015. Usulan Peningkatan Overall Equipment Effectiveness (OEE) Pada Mesin Tapping Manual Dengan Meminimumkan Six Big Losses. Jurnal Online Institut Teknologi Nasional Reka Integra ISSN : 2338-5081, Jurusan Teknik Industri, Institut Teknologi Nasional (Itenas), No.03, Vol.03, Bandung.

Dinda HT, Arif R, Ceria FM. 2013. Analisis Overall Equipment Effectiveness (OEE). Jurnal Teknik Industri, Jurusan Teknik Industri, Universitas Brawijaya.

Gazpers, V. 2002. Metode Analisis Untuk Peningkatan Kualitas. Gramedia Pustaka Utama, Jakarta.

Hermanto. 2016. Pengukuran Nilai Overall Equipment Effectiveness (OEE) Pada Divisi Painting di PT. AIM. Jurnal Metris, 17 (2016): 97 - 106, Program Studi Teknik Industri, FTMIPA, Universitas Indraprasta PGRI, Jakarta. 